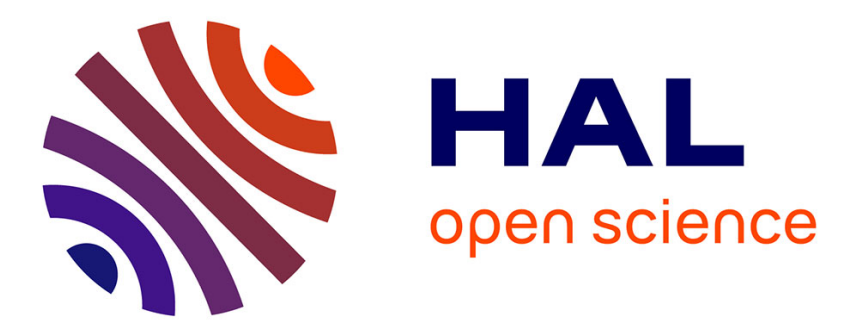

\title{
Accelerometry predicts prey-capture rates in the deep-diving king penguin Aptenodytes patagonicus
}

Émile Brisson-Curadeau, Yves Handrich, Kyle H Elliott, Charles-André Bost

\section{To cite this version:}

Émile Brisson-Curadeau, Yves Handrich, Kyle H Elliott, Charles-André Bost. Accelerometry predicts prey-capture rates in the deep-diving king penguin Aptenodytes patagonicus. Marine Biology, 2021, 168 (10), pp.156. 10.1007/s00227-021-03968-y . hal-03457089

\section{HAL Id: hal-03457089 \\ https://hal.science/hal-03457089}

Submitted on 8 Feb 2022

HAL is a multi-disciplinary open access archive for the deposit and dissemination of scientific research documents, whether they are published or not. The documents may come from teaching and research institutions in France or abroad, or from public or private research centers.
L'archive ouverte pluridisciplinaire HAL, est destinée au dépôt et à la diffusion de documents scientifiques de niveau recherche, publiés ou non, émanant des établissements d'enseignement et de recherche français ou étrangers, des laboratoires publics ou privés. 


\title{
Accelerometry predicts prey-capture rates in the deep-diving king penguin Aptenodytes patagonicus
}

\author{
ÉmileBrisson-Curadeau ${ }^{1,2} \odot$ YvesHandrich $^{3} \cdot K_{\text {KyleH. Elliott }}^{2} \cdot$ Charles-AndréBost $^{1}$
}

Received:30 April2021/Accepted: 8September 2021

\begin{abstract}
Remotely estimating prey-capture rates in wild animals is key to assess foraging success. In diving animals, accelerometers have been particularly useful to remotely detect prey captures and have been shown to be more precise than traditional estimates relying on depth-derived measures (e.g., wiggles). However, validations of the accelerometry technique using a gold standard (i.e., with supervision) have been mostly restricted to shallow diving species, which can be equipped with cameraloggers for visual validation of prey-capture events. In species diving near the euphotic limit (150-200 m), accelerometers remain mostly untested due to the difficulty of validating such methods in darkness at extreme depth in the wild. In addition, prey-pursuits in low-light conditions might not result in intense and long-duration acceleration signatures, as predator-prey perception likely occurs at close-range in the dark (i.e., the "visual-interactions hypothesis"). We combined accelerometers with beak-opening sensors (for validation) and depth recorders on a wild deep-diving seabird, the king penguin Aptenodytes patagonicus, to describe prey captures at depth and create predictive models using accelerometers. Surprisingly, prey pursuits and captures were similar in duration $(3.9 \pm 3.5 \mathrm{~s})$ and intensity $(0.78 \pm 0.31 \mathrm{~g})$ as shallow-diving species reported by similar studies. As accelerometry signatures were distinct, accelerometry-derived variables were almost twice as accurate (Meansquared error $=8.6$ ) at predicting prey-capture events as depth-derived variables ("wiggles", Mean-squared error $=16.0$ ). As in the shallow-diving species, accelerometry outperforms traditional depth-derived models at measuring the foraging intake in deep-diving animals, highlighting the usefulness of accelerometers for measuring animal behavior.
\end{abstract}

Keywords King penguin $\cdot$ Diving seabird $\cdot$ Accelerometer $\cdot$ Prey capture $\cdot$ Wiggle $\cdot$ Machine learning

\section{Introduction}

Knowing where and when animals forage is an important aspect in ecology and conservation (Grémillet et al. 2004; Pichegru et al. 2010; Scheff et al. 2010, Hays 2016). In deep-diving species, the identification of foraging hotspots

Responsible Editor: T.A. Clay.

Responsible Editor: T.A. Clay Reviewers:undisclosed experts.

* Émile Brisson-Curadeau emile.brissoncuradeau@mail.mcgill.ca

1 Centre d'Etudes Biologiques de Chizé, CNRS, UMR 7372, 79360 Villiers en Bois, France

2 Université McGill, 21111 Lakeshore Road, Sainte-Anne-de-Bellevue, Quebec H9X 3V9, Canada

3 CNRS, IPHC UMR 7178, Université de Strasbourg, 67000 Strasbourg, France has been mainly facilitated by the analysis of horizontal movements obtained from satellite or GPS technology (e.g., Trathan et al. 2008; Zimmer et al. 2008). Analytical techniques applied to horizontal movements employ animal's speed, tortuosity, and step length to define Area Restricted Searches (ARS) and determine whether the animal is travelling or foraging (Fauchald and Tveraa 2003; Langrock et al. 2012).

As recent bio-logging devices record much more information than just the location of an animal, several devices, such as camera loggers, mouth opening sensors, temperature loggers inserted in the digestive track, depth loggers and accelerometers, have been used to remotely assess foraging success (e.g., prey capture rate) in diving animals (Kokobun et al. 2011; Viviant et al. 2014; Volpov et al. 2015). In addition, some species-specific methods have been used, such as buoyancy change in seals (Adachi et al. 2021), echolocation clicks in whales (Miller et al. 2004) and visceral warming in tunas (Bestley et al. 2008). While most of these approaches 
are in theory widely applicable across taxa, their use has been limited, because their deployment on wild animals can be challenging. For instance, mouth opening sensors use a magnet on one part of the mouth and a Hall sensor on the opposing part to detect whenever the animal opens its mouth or beak, and are typically a precise and powerful tool to detect prey captures (Wilson et al., 2002; Hanuise et al. 2010; Viviant et al. 2014). However, the equipping of these loggers can require invasive surgical procedures to conceal beneath the skin the electrical lead between the Hall sensor and data logger. Temperature loggers detect drops in temperature in the oesophageal track due to the ingestion of prey. While these loggers provide very good estimates of prey-capture rates, they are again quite invasive for the animal (Charrassin et al. 2001; Horsburgh et al. 2008). Furthermore, only a small proportion of Hall sensors or temperature loggers deployed provide useful information, due to difficulties with wiring or retrieval (Charrassin et al. 2001; Wilson et al. 2002).

Camera loggers attached to the back or head of the animal have been used more recently, with high-quality miniature cameras now available on the market (Kokobun et al. 2011; Watanabe and Takahashi 2013; Watanabe et al. 2014; Volpov et al. 2015). However, success of this method on deepdiving animals is mixed, as prey captures are not systematically detected at low-light depths, despite the use of external LEDs (Naito et al. 2013, Brisson-Curadeau et al. 2019). For this reason, camera-loggers equipped on deep-diving animals have been mostly used to evaluate the diet of an animal - which requires only a few "good" pictures/footage to be assessed - rather than systematically quantifying prey capture (Naito et al. 2013, Naito et al. 2017, Adachi et al. 2021, Yoshino et al. 2020; but see Watanabe et al. 2020).

As most of the previously described approaches are difficult to apply in the field, the use of depth profiles has been historically one of the most widely used methods to estimate prey capture in deep-diving animals (e.g., Kirkwood and Robertson 1997; Zimmer et al. 2011; Hanuise et al. 2013; Scheff et al. 2016). Depth loggers are generally easy to deploy and can provide information on foraging behavior. In particular, many derived variables (descent angle, maximum depth, dive shape, etc.) are indicative of foraging dives (Schreer et al. 1996; Halsey et al. 2007, 2010). The presence of short up-and-down motions (called "wiggles", see Fig. 1) has been particularly used in the literature to estimate the number of prey captures in a dive (e.g., Charrassin et al. 2001; Bost et al. 2007; Zimmer et al. 2011; Scheffer et al. 2016; Tessier \& Bost 2020). Other commonly used depth-derived variables include maximum depth, dive duration and dive shape, where deeper dives with proportionally longer bottom time are indicative of increased feeding activity (Ropert-Coudert et al. 2000; Mori et al. 2002; Elliott et al. 2008). While these variables are easy to collect
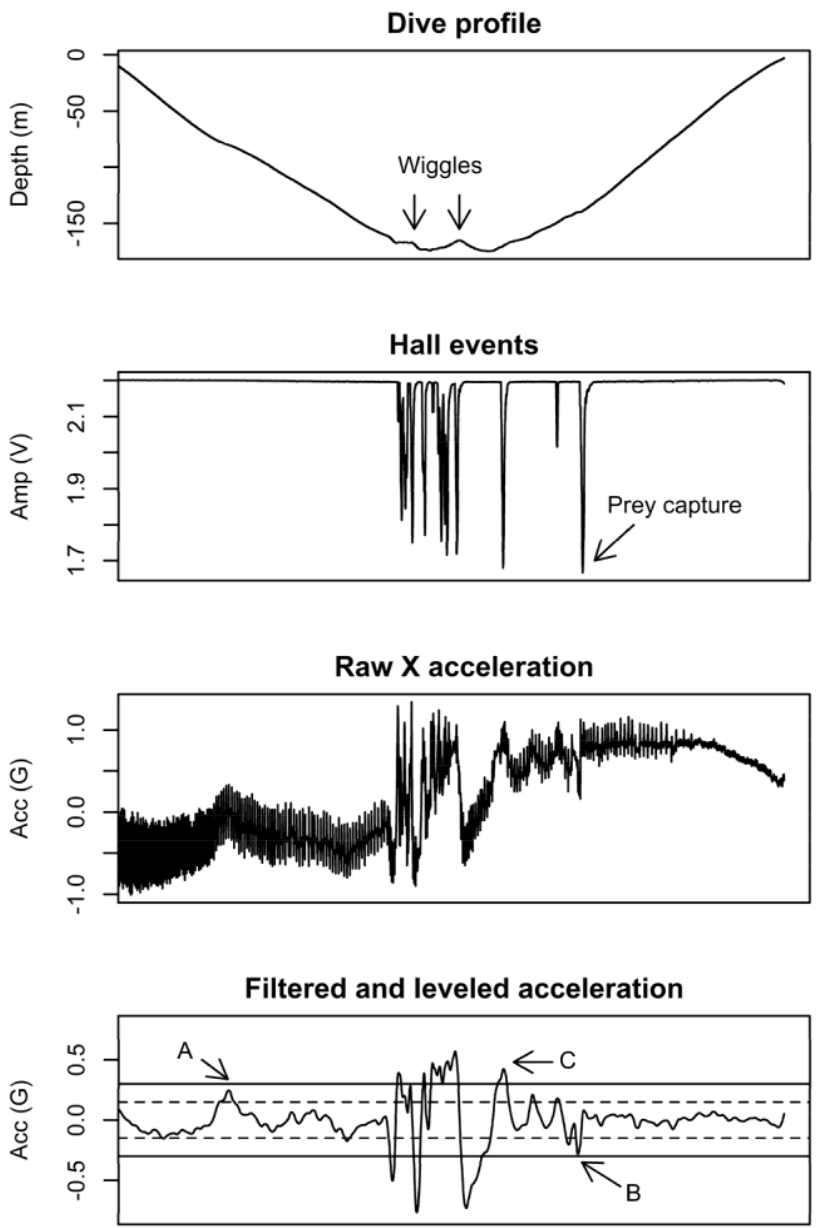

Fig. 1 Depth-profile, Hall events, raw acceleration and filtered acceleration of a representative king penguin dive. Point A represents a false positive under the $0.15 \mathrm{~g}$ threshold, but a true negative under the $0.3 \mathrm{~g}$ threshold. Point $\mathrm{B}$ represents a true positive under the $0.15 \mathrm{~g}$ threshold, but a false negative under the $0.3 \mathrm{~g}$ threshold. Point $\mathrm{C}$ represents a true positive under both thresholds

and compute, their accuracy to quantify prey capture can be rather low, at least in some species (Bost et al. 2007; Hanuise et al. 2010; Carroll et al. 2014).

Accelerometers, such as depth loggers, are small and easily deployable, with few effects on the fitness of the equipped animal (Chivers et al. 2016). They can detect movement in three dimensions ( $\mathrm{x}, \mathrm{y}$ and $\mathrm{z}$ axis) and at a higher resolution than depth loggers, therefore, providing more information on the behavior of the animals. Moreover, recent studies have shown accelerometers to be more accurate at estimating prey capture than the traditional use of wiggles (e.g., Del Caño et al. 2021). Consequently, their use to quantify prey capture has been increasing in the past few years (Gallon et al. 2013; Carroll et al. 2018; Yoshino et al. 2020). Yet, testing the accuracy of accelerometry at predicting foraging events in the wild has been mainly limited to animals diving above $100 \mathrm{~m}$ depth (hereafter referred as "shallow-diving 
species"), mostly feeding on plankton and crustaceans, with validation on camera loggers (Kokobun et al. 2011, Watanabe and Takahashi 2013; Watanabe et al. 2014; Sato et al. 2015; Volpov et al. 2015). While acceleration has been used on deep-diving animals to compute prey-capture rates (Yoshino et al. 2020; Adachi et al. 2021), true validation at deeper depths is rare in the literature, because low-light conditions limit the potential of camera loggers for validation (but see Watanabe et al. 2020). In addition, it is possible that prey-pursuits near or below the limit of the euphotic zone are shorter in duration and amplitude, as predator-prey perception occurs at closer range. The "visual-interaction hypothesis" states that since the escape behavior is less efficient at depth due to reduced detection distance by both prey and predator, deep ectothermic fish are less reactive and have a low metabolism (Childress et al. 1990; Drazen and Seibel 2007). This could potentially reduce the detectability of prey-capture attempts in the acceleration signal, as predators do not need dynamic chases to capture prey.

The objective of this study is to validate the use of accelerometry as a reliable tool to estimate prey-capture rate in a deep-diving bird. We first aim to describe the typical preycapture acceleration signature at depth, and evaluate whether the "visual-interaction hypothesis" complicates detection of prey capture as depth increases. We predict that deeper captures will generate acceleration peaks with a lower amplitude and duration than shallower captures. Second, we aim to build a model predicting prey capture using accelerometry data as inputs. We chose machine learning algorithms to compute our model, as their outputs are typically more accurate than those of linear models-especially when fed with a high data volume like that of accelerometry data - and hence have been increasingly used to convert accelerometry signals into behavioral classification (Brewster et al. 2018; Pucci et al. 2020; Sutton et al. 2020). The validation of such algorithms requires a gold standard, which can be done in deep-diving seabirds using either beak-opening sensors or esophageal temperature sensors. We use a unique data set that combines a beak-opening sensor and a 1D-accelerometer on the wild king penguins (Aptenodites patagonicus), and compare our results with the traditional methods using wiggles and other depth-derived variables.

\section{Methods}

The data set was collected in February and March 2006 on Possession Island, Crozet $\left(46.4^{\circ} \mathrm{S}, 51.8^{\circ} \mathrm{E}\right)$, and was used by Hanuise et al. (2010) to compare wiggles and a combination of two sensors measuring esophageal temperature and beakopening amplitude to detect prey captures. While acceleration data was also collected, it was unused in Hanuise et al. (2010) study. The ethics committee of the Institut polaire français Paul-Émile Victor approved all fi procedures. All analysis were conducted using $\mathrm{R}$ version 4.0.3 (R Core Team 2020).

Two brooding king penguins (named E1 and H1) were equipped with one SMAD data logger (DEPE-IPHC, France) attached externally to their back. The SMAD is a TDR equipped with a single axis accelerometer (capturing the surge or $\mathrm{x}$ axis) and a long and single connector, buried under the skin from the back to the corner of the beak. From this position, one temperature probe was inserted $10 \mathrm{~cm}$ depth inside the esophagus, while a Hall sensor was glued on the orange tip of the mandible, just in front of a miniaturized magnet, glued on the maxilla. Depth and esophageal temperature were continuously recorded at $2 \mathrm{~Hz}$, while beakopening amplitude and acceleration were recorded at $16 \mathrm{~Hz}$ during two daily periods of $1 \mathrm{~h}$ starting at $7 \mathrm{AM}$ and $4 \mathrm{PM}$. Only dives with a maximal depth deeper than $40 \mathrm{~m}$ were considered in our analysis, as shallower dives in king penguins are travelling or exploratory dives not associated with foraging and only anecdotally contain prey captures. King penguins prey are quasi absent in the $0-70 \mathrm{~m}$ depth range during the day (Bost et al. 2002). For this reason, shallow dives in this species are often removed from foraging analysis (e.g., Hasley et al. 2010; Le Vaillant et al. 2013; Scheffer et al. 2016; Tessier and Bost 2020). Indeed, only $0.39 \%$ of all prey captures in our data set occurred above $40 \mathrm{~m}$.

Because Hall sensors were determined to be the most accurate method to detect prey capture in the earlier study (Hanuise et al. 2010), we ignore esophageal sensors in this study and used prey-capture events recorded by the Hall sensors as the gold standard. In any cases, both esophageal sensor and Hall sensor provide similar estimations of prey capture (Hanuise et al. 2010).

\section{Accelerometry data}

Raw acceleration profiles for each dive were filtered twice with two different Local Polynomial Regressions using the "loess" function available in R. Loess is a nonparametric method using locally weighted polynomial regressions to fi a smooth curve through datapoints (Cleveland et al. 1992). The smoothness of the curve is decided by the alpha parameters, which controls the size of the sliding widow that locally fits the regressions. Alpha $=1.0$ means that the sliding widow is as wide as the data (smoother curves), while alpha $=0.0$ means that the window includes only one point at a time (coarser curve).

The first filter was used to remove the pitch signal from the 1-D accelerometry data. We, therefore, ran the first Loess with a running window of $120 \mathrm{~s}$ (alpha $\approx 0.4$ ), determined empirically to capture general trends in acceleration due to changes in main directional pitch during the dive. We ran a second Local Regression with a running window of 
$6 \mathrm{~s}$ (alpha $\approx 0.02$ ) to remove wing beat noise, leaving only the pitch variation plus medium-scale peaks, assumed to be mostly associated with prey captures. The final output was obtained by subtracting the $6 \mathrm{~s}$-window regression (pitch plus prey-capture acceleration) from the $120 \mathrm{~s}$-window regression (pitch only), leaving solely the acceleration peaks that we hypothesized were mostly associated with prey capture (see Fig. S1 for a graphical representation of the twofilter method).

Once we fi ed the acceleration profi we visually scanned a sample of all prey-capture events to determine which parameters could be used by the machine learning (ML) algorithm to automatically detect prey captures. We determined that feeding events caused acceleration peaks, either of positive or negative force, of at least $\pm 0.15 \mathrm{~g}$, with varying maximal intensity but rarely over $\pm 1.2 \mathrm{~g}$. By counting peaks above/below $\pm 0.15 \mathrm{~g}$, we, therefore, concluded that the ML algorithm would detect nearly all capture events. However, preliminary analyses also showed that some acceleration peaks above/below $\pm 0.15 \mathrm{~g}$ were not related to feeding events, potentially leading to false positive errors by the algorithm. Fortunately, these peaks were rarely above/ below $\pm 0.35 \mathrm{~g}$. We, therefore, used two distinct values to feed the algorithm: a conservative threshold, a high value that would reduce the amount of false positive but omit true positives, and a liberal threshold, that would potentially include all true positives but allow false positives as well. To determine the best values for these two thresholds, we ran the ML algorithm with all combinations of values between $\pm 0.15 \mathrm{~g}$ and $\pm 0.40 \mathrm{~g}$ in incrementation of $0.05 \mathrm{~g}$ and determined which combination gave the best results. The threshold duo of $\pm 0.15 \mathrm{~g}$ and $\pm 0.30 \mathrm{~g}$ were thereby determined to be the best combination (see Fig. 1).

\section{Diving data and Hall events}

Wiggles are defi as an increase in the depth, followed by a decrease and another increase, creating a bump in the profile (Schreer et al. 1996; Halsey et al. 2007). We used the method for king penguins described in Bost et al. (2007) to automatically detect wiggles in our data set, with a minimal threshold of $2 \mathrm{~m}$ in vertical deviation for depth deviations to be considered wiggles. We also calculated the proportion of the dive occurring in the bottom phase, which is an index of dive shape (Halsey et al. 2007). The bottom of the dive was defined as the dive portion occurring below $90 \%$ of the maximum depth (Bost et al. 2007).

Hall events from beak-opening sensors were classifi as type A and B using Hanuise et al. (2010). Type A Hall events are very short beak opening of less than a second of duration and are associated with non-feeding beak opening (i.e., unsuccessful attempts). Type B are longer (>1 s) beak opening events associated with prey capture and handling, as validated with esophageal temperature sensors (Hanuise et al. 2010). Only type B events were considered for analysis and will refer to the gold standard of a feeding event, i.e., successful feeding attempts.

\section{Machine learning algorithm and linear models}

Four neural networks were designed to evaluate the efficiency of accelerometry-derived data compared with depthderived data to predict the number of prey capture per dive. All neural networks consisted of one layer and ten nodes, with Hall events used as gold standard. The first neural network (named "NN1") used the two accelerometry variables (number of peaks above/below $\pm 0.15 \mathrm{~g}$ and $\pm 0.3 \mathrm{~g}$ per dive) as inputs. First, 65\% of the data set (both birds combined) was used to train the algorithm. Then, the algorithm was tested on the remaining $35 \%$ of the data set. Because our sample size of different birds is small $(n=2)$, we also made a diff ent neural network with accelerometry data (NN2) which we trained on one bird and tested on the other, so that we could further assess inter-individual variability. The third and fourth neural networks (NN3 and NN4) used two of the most common depth-derived variables as predictors of prey captures: number of wiggles and dive-shape per dives. As with the accelerometer-derived variables, one model used $65 \%$ to predict the remaining $35 \%$ (NN3), while the other used one bird as training to predict the other (NN4). Package neuralnet was used to create neural network models (Günther and Fritsch 2010).

We made a fifth model, a linear model labelled "LM1", which only used wiggles as predictors. The linear model using wiggles is, to our knowledge, the most widely used method in the literature to directly estimate prey capture in penguins (e.g., Bost et al. 2007; Zimmer et al. 2011; Hanuise et al. 2013; Scheffer et al. 2016; Tessier and Bost 2020). The linear model served as the "traditional" method and was directly compared with our neural network models using standardized metrics (see the next section).

\section{Model validation and statistics}

To test whether the "visual-interaction hypothesis" infl enced the acceleration signatures, we compared acceleration peaks associated with prey captures below or near the euphotic limit $(>150 \mathrm{~m}$ ) with those in shallower water $(<150 \mathrm{~m})$. We used a Student's $t$ test to assess the difference in peak amplitudes (absolute value) and durations between those two groups.

To compare capture-rate prediction models, we calculated the Mean Square Error (hereafter "MSE") of all five models. We also modeled the predicted outputs of the fi e models over the observed values (Hall sensor data) using linear models and compared those outputs with the 1:1 
regression. Finally, we calculated the $R^{2}$ of each regression to evaluate dispersion of the predictions (as done in Bost et al. 2007 and Hanuise et al. 2010). Direct comparison with two other studies using wiggles as predictors on king penguins were possible using the slope, origin and $R^{2}$ of the regressions of the predicted over observed values (Bost et al. 2007; Hanuise et al. 2010).

\section{Results}

The loggers recorded 206 dives deeper than $40 \mathrm{~m}$. The bird labelled E1 recorded 127 dives over 8 days of foraging, while $\mathrm{H} 1$ recorded 79 dives over 8 days. Mean maximal dive depth was $113 \pm 34 \mathrm{~m}$ (range: $40-219 \mathrm{~m}$ ). The average number of Hall events $B$ in a dive was $3.70 \pm 6.92$ (range: 0-46), while the average number of wiggles was $0.95 \pm 1.23$ (range: $0-7$ ). Acceleration peaks associated with prey captures were on average $0.78 \pm 0.31 \mathrm{~g}$ in maximum amplitude and $3.9 \pm 3.5 \mathrm{~s}$ in total duration. There was no signifi diff ence between the maximum intensity of peaks occurring below $150 \mathrm{~m}$ and those occurring above $150 \mathrm{~m}\left(t_{176}=-0.33, p=0.74\right)$, but acceleration peaks occurring above $150 \mathrm{~m}$ were shorter in duration compared to deeper peaks (above: $3.8 \mathrm{~s} \pm 3.4$, below: $4.8 \mathrm{~s} \pm 4.2$, $\left.t_{170}=-2.96, p=0.004\right)$.

Using the $\pm 0.3 \mathrm{~g}$ or the $\pm 0.15 \mathrm{~g}$ threshold, the number of accelerometry peaks in a dive was highly correlated with the number of Hall events-B (Fig. 2). As expected, the number of peaks beyond $\pm 0.3 \mathrm{~g}$ slightly underestimated the number of Hall events, while the $\pm 0.15 \mathrm{~g}$ threshold slightly overestimated the number of Hall events.

Models with accelerometry-derived variables (NN1 and NN2) scored signifi y better than those with depthderived variables (NN3 and NN4) in all metrics (Table 1, Fig. 3). For models NN2 and NN4, bird H1 was used as the training data set, as the number of dives performed was comparable to the sample size of the training data set for model NN1 and NN3 (127 dives for NN2/NN4, 132 for NN1/NN3). The two models which used accelerometryderived data had similar accuracy $(\Delta 4.5$ in MSE, $\Delta 0.12$ in $R^{2}$ ). In contrast, the diff ence between depth-derived models NN3 and NN4 was much greater $(\Delta 25.4$ in MSE, $\Delta 0.24$ in $R^{2}$ ).

The traditional approach, with a linear model using only the number of wiggles as predictor, did poorly compared to most neural network models $(\mathrm{MSE}=32.4$, slope $=0.32 \pm 0.06$, intercept $=2.5 \pm 0.50, R^{2}=0.32$, see Fig. 4). Nonetheless, the $R^{2}(0.32)$ was similar to other studies that used similar methods (Bost et al. 2007: 0.26, Hanuise et al. 2010: 0.39).
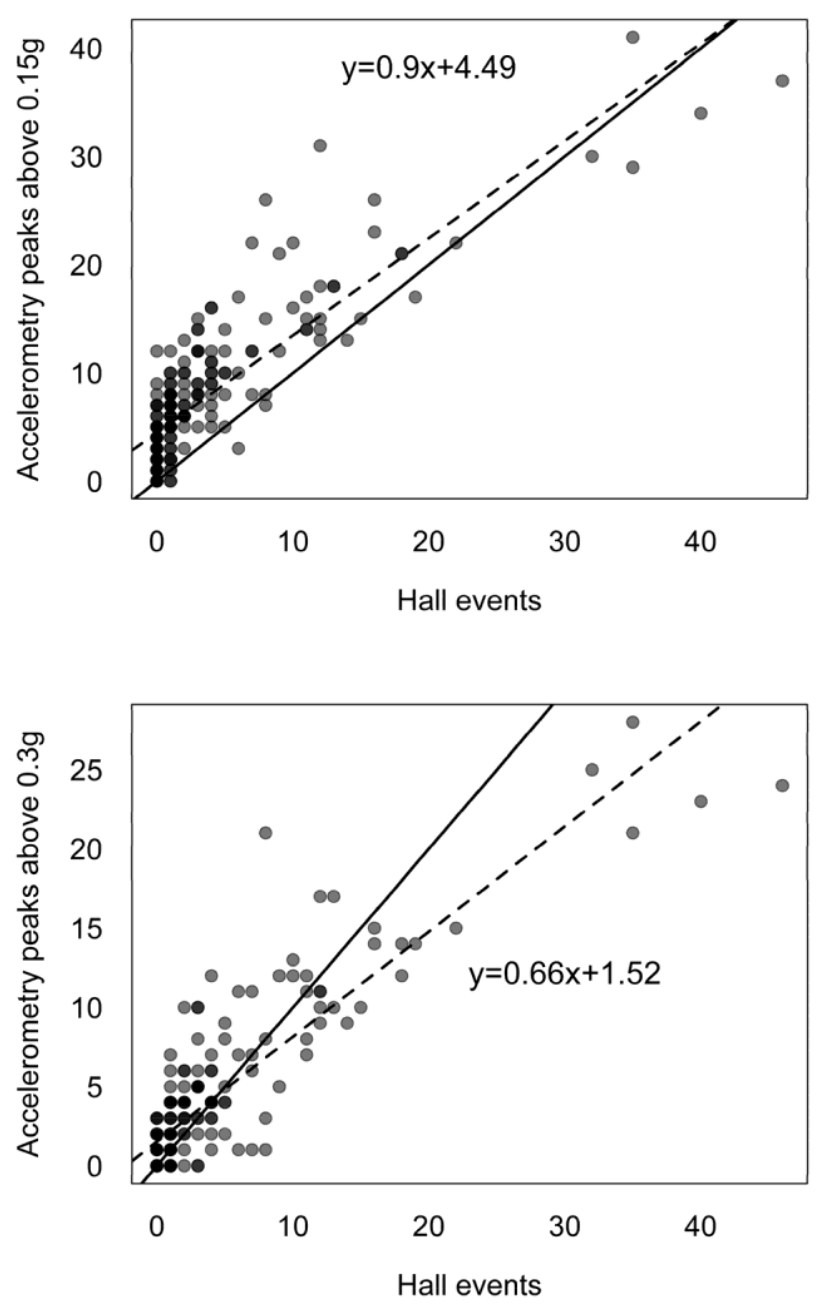

Fig. 2 Number of acceleration peaks in a king penguin dive relative to the number of Hall events (dotted line) compared to the 1:1 line (solid line). The $0.15 \mathrm{~g}$ threshold (top panel) slightly overestimates the number of captures, while the $0.3 \mathrm{~g}$ threshold (bottom panel) underestimates the number of captures over most of the regression. Darker data points show overlapping values

\section{Discussion}

Prey captures at depth in the king penguin produced discernable acceleration signatures of considerable intensity and length. Furthermore, neural networks using acceleration inputs accurately predicted the number of prey-capture events in a dive. These results add to the growing number of studies showing the benefi of using accelerometry to predict prey capture (e.g., Gallon et al. 2013, Kokobun et al. 2011, Watanabe and Takahashi 2013, Watanabe et al. 2014, Sato et al. 2015, Volpov et al. 2015, Carroll et al. 2018, Yoshino et al. 2020, Adachi et al. 2021), and provides one of the first validations for deep-diving species. Our models were significantly more accurate than the previous studies using depth-derived variables on king penguins. 
Table 1 Model outputs predicting prey captures (Hall sensor data) using either acceleration-derived or depth-derived data

\begin{tabular}{|c|c|c|c|c|c|c|c|c|}
\hline Model & Variable & Training dataset & Validation dataset & Slope & Intercept & $R^{2}$ & $\begin{array}{l}\text { Mean } \\
\text { Square } \\
\text { error }\end{array}$ & Graph \\
\hline Neural Network 1 & $\begin{array}{l}\text { Accelerometry } \\
\text { derivaed }\end{array}$ & $\begin{array}{l}65 \% \text { of dataset } \\
\quad(n=132)\end{array}$ & $\begin{array}{l}35 \% \text { of dataset } \\
\quad(n=72)\end{array}$ & $0.88 \pm 0.12$ & $0.6 \pm 0.8$ & 0.79 & 8.6 & Figure 2 \\
\hline Neural Network 2 & $\begin{array}{l}\text { Accelerometry } \\
\text { derivaed }\end{array}$ & $\begin{array}{l}\text { Bird E1 ( } n=127 \\
\text { dives) }\end{array}$ & $\begin{array}{l}\text { Bird H1 }(n=79 \\
\text { dives) }\end{array}$ & $0.96 \pm 0.15$ & $1.0 \pm 1.0$ & 0.67 & 13.1 & Figure $3 \mathrm{a}$ \\
\hline Neural Network 3 & Depth-derived & $\begin{array}{l}65 \% \text { of dataset } \\
\quad(n=132)\end{array}$ & $\begin{array}{l}35 \% \text { of dataset } \\
(n=72)\end{array}$ & $0.51 \pm 0.11$ & $1.8 \pm 0.8$ & 0.52 & 16.0 & Figure $2 b$ \\
\hline Neural Network 4 & Depth-derived & $\begin{array}{l}\text { Bird E1 }(n=127 \\
\text { dives) }\end{array}$ & $\begin{array}{l}35 \% \text { of dataset } \\
\quad(n=79 \text { dives })\end{array}$ & $0.75 \pm 0.24$ & $3.6 \pm 1.5$ & 0.28 & 41.4 & Figure $3 b$ \\
\hline Linear Model 1 & Wiggle & Whole dataset & Whole dataset & $\begin{array}{l}\text { This study: } \\
0.32 \pm 0.6 \\
\text { Bost et al. } \\
\text { 2007:0.45 } \\
\text { Hanuise } \\
\text { et al. } \\
\text { 2010: } 0.8\end{array}$ & $\begin{array}{l}\text { This study: } \\
2.5 \pm 0.5 \\
\text { Bost et al. } \\
\text { 2007:1.77 } \\
\text { Hanuise } \\
\text { et al. } \\
\text { 2010: } 1.82\end{array}$ & $\begin{array}{l}\text { This study: } \\
0.32 \\
\text { Bost et al. } \\
\text { 2007:0.26 } \\
\text { Hanuise } \\
\text { et al. } \\
\text { 2010: } 0.39\end{array}$ & 32.3 & Figure 4 \\
\hline
\end{tabular}

Validation variables are calculated on the prediction observation relationship
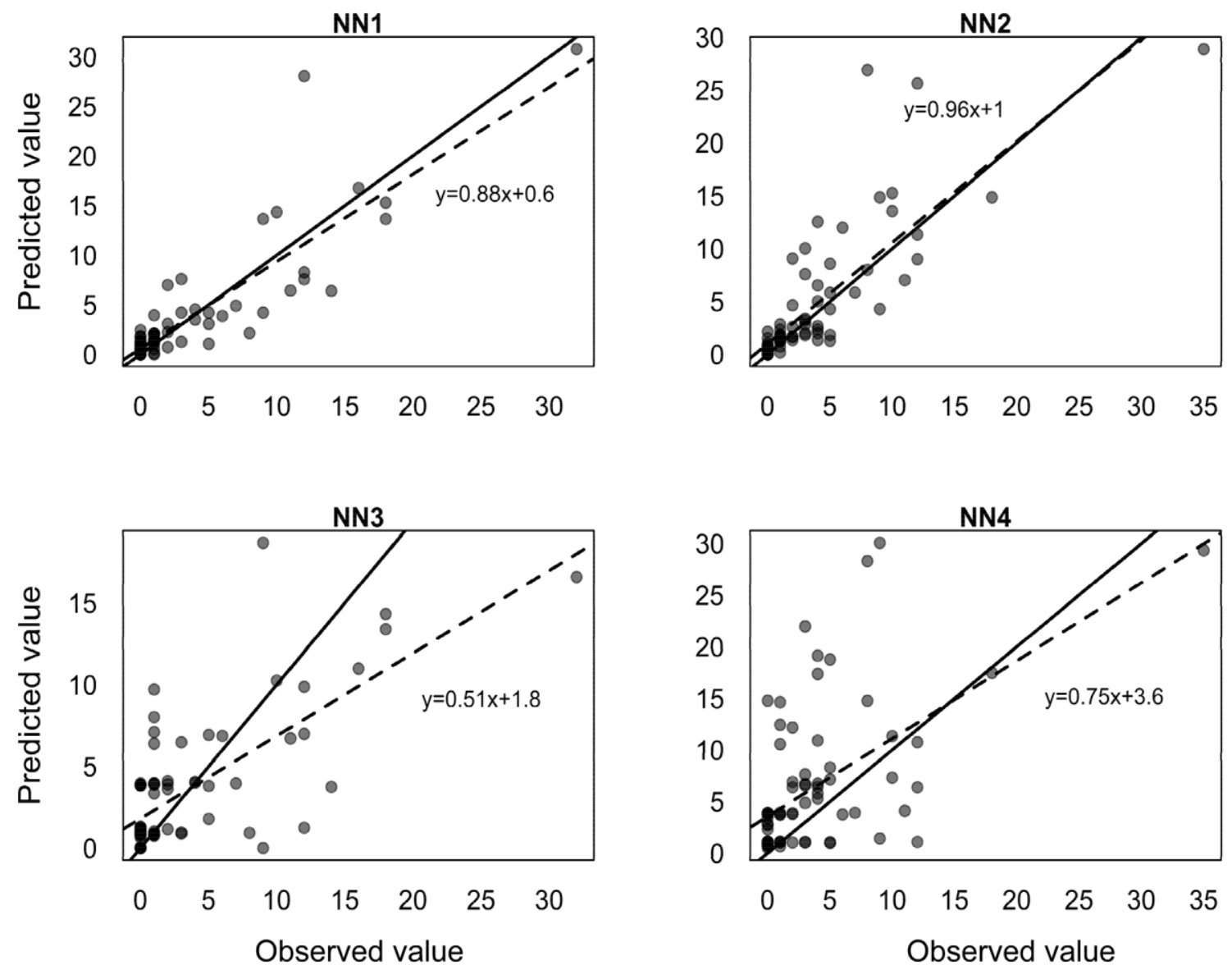

Fig. 3 Predicted relative to observed prey-capture rates for king penguins from all four neural network models (dotted lines) compared to the 1:1 line (solid lines). Models NN1 and NN2 used accelerometryderived variables as predictors, while models NN3 and NN4 used

depth-derived variables. Models NN1 and NN3 were trained and validated with data from both birds combined, while models NN2 and NN4 trained with one bird and validated with another. Darker data points show overlapping values 


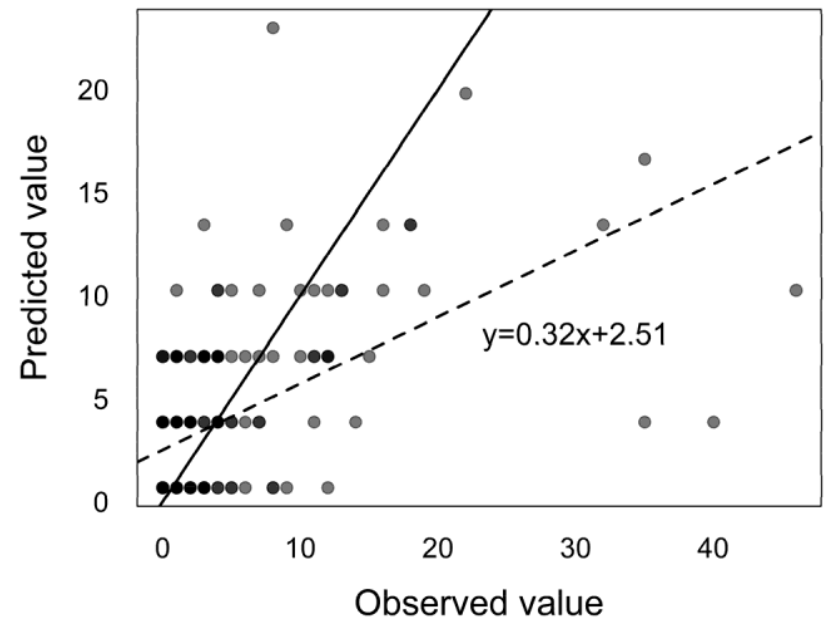

Fig. 4 Predicted relative to observed prey-capture rates for king penguins (dotted line) compared to the 1:1 line (solid line) for the traditional linear model using the number of wiggles in a dive as the explanatory variable. Darker data points show overlapping values

\section{Acceleration signature of prey captures}

The "visual-interaction hypothesis" stipulates that, at depth, the escape behavior of fish is less effective, as predator-prey detection occurs so close that evasion is futile (Childress et al. 1990; Drazen and Seibel 2007). This, combined with a lower water temperature at depth, leads fish such as myctophids to reduce their metabolism when in deeper, dark waters (Drazen and Seibel 2007; Catul et al. 2011). In contrast, fish well above the euphotic zone have high metabolism to accommodate a more explosive escape response. King penguins feed on mesopelagic myctophids near or below the euphotic zone and exclusively use vision to detect their prey (Martin 1999; Bost et al. 2002; Cherel et al. 2007). It was, therefore, expected that the acceleration needed to pursue and capture prey would not contrast well with the acceleration noise of regular underwater movements. This was not the case, as the filtered acceleration peaks associated with prey capture was discernable ( $0.78 \mathrm{~g}$ in average) and total pursuit and capture time lasted several seconds ( $3.9 \mathrm{~s}$ in average). This is comparable to similar-size seabirds diving closer to the surface: the surge acceleration of Magellanic penguins Spheniscus magellanicus when capturing schooling fish averaged $0.31-0.64 \mathrm{~g}$ in maximum amplitude, while the optimal tri-axial acceleration thresholds for detecting fi captures in Adelie penguins Pygoscelis adeliae were $0.25-0.45 \mathrm{~g}$, similar to our $0.15 \mathrm{~g}$ and $0.30 \mathrm{~g}$ thresholds for surge acceleration (Watanabe and Takahashi 2013; Del caño et al. 2021). Both of these penguins feed on fi in shallow waters above $50 \mathrm{~m}$. Similarly, prey chase and capture in the little penguin Eudyptula minor averages $2.9 \pm 3.3 \mathrm{~s}$, which is quite similar to our results (Ropert-Coudert et al.
2006). Obviously, the prey-capture acceleration signature associated with different predator species depends on much more than solely the depths at which they forage. Predator and prey size, diving speed and foraging tactics are all factors that could influence the prey-capture signatures. Further study is needed to assess whether, with a larger species sample size, deeper species will tend to display fainter acceleration signatures compared to shallow-diving species.

Another unexpected result was the signifi diff ence between the duration of prey captures occurring above and below $150 \mathrm{~m}$, with shallower captures taking less time than deeper captures. The opposite result was anticipated by the visual-interaction hypothesis assuming that darkness reduces chasing initiation distance. However, king penguins may opportunely feed on smaller fish larvae and/or plankton when diving in shallow water. These prey types, which are more abundant near the surface, might not require great acceleration to be captured. On the other hand, larger fi near the euphotic zone targeted by the penguin might be more mobile, especially considering that these fish initiate vertical migration at night. Even in poor light conditions, the prey might require considerable acceleration to be captured compared to fish larvae and plankton in shallow waters. Further study is needed to validate this idea.

\section{Advantage of accelerometry data to estimate feeding activity}

Accelerometers provide one of the most convenient and accurate methods to estimate prey capture (Watanabe \& Takahashi 2013; Volpov et al. 2015; Del Caño et al. 2021). They are small and can be deployed with relative ease, while their low power consumption allows for extensive data recording. However, validation of accelerometry requires a gold standard, which is often easier obtained using cameraloggers. Hence, most validations of accelerometry on wild animals have been conducted on shallow divers feeding in the euphotic zone (e.g., pygoscelid penguins: Watanabe et al. 2014, fur seals: Volpov et al. 2015, Del magellanic penguin: Caño et al. 2021).

While deep-divers feeding on mesopelagic fi are a crucial key to understand food-chain mechanisms in the open-ocean, the use of accelerometry to quantify foraging success is recent in these species (Watanabe et al. 2020; Yoshino et al. 2020; Adachi et al. 2021). Furthermore, true validation with a gold-standard is very rare: Watanabe et al. (2020) showed that the number of accelerometry peaks was highly correlated with the number of video-confirmed feeding events in a deep-diving pinniped. Yet again, the heavy camera-loggers used in their study would exceed $3 \%$ of body mass ethical guidelines to equip on deep-diving birds, such as Uria alcids and Aptenodytes penguins. For this reason, foraging activity and success on these species have been 
almost exclusively determined using depth-derived variables (Kirkwood and Robertson 1997; Zimmer et al. 2011; Hanuise et al. 2013; Scheffer et al. 2016; Orgeret et al. 2019; Tessier and Bost 2020). Accelerometry provides a more accurate alternative: our results show that accelerometry greatly outperforms wiggles in quantifying foraging success. Even foraging activity cannot be determined accurately with depth-derived variables, as many deep-dives-some even containing wiggles - were not associated with prey captures in our study (see Fig. 4). Therefore, identification of foraging dives cannot be made reliably with depth-derived variables, such as wiggles. By combining a conservative acceleration threshold at $\pm 0.3 \mathrm{~g}$ with a more liberal one at $\pm 0.15 \mathrm{~g}$, we were able to obtain accurate machine-learning models for the king penguin that surpassed the wiggle method.

\section{Limitations and next step}

While neural networks are superior than linear models at making accurate predictions, they are usually more so with very large sample sizes and many input variables (Bonaccorso 2017). Our sample size was moderate in size and only two variables were used as inputs. Ideally, a larger sample size would likely increase the accuracy of the algorithm, fully taking advantage of the ML method. Data on more individuals is necessary for better testing of the inter-individual variability.

One limitation of our method is the pre-determination of the acceleration thresholds to identify acceleration peaks. These thresholds likely differ from one species to another. Repeating the experiment for each species would provide accurate estimates of prey-capture rate, but would be unrealistic considering the difficulty of obtaining gold standard data. Depth-derived variables also suff from the same fl ws and need species-specifi validations; the minimum deviation for a change in the depth profile to be considered a wiggle is species-specific (Hasley et al. 2007). Nonetheless, these values are often easy to determine without validation by simply looking at trends in the depth-profi data (e.g., Zimmer et al. 2011; Crossin et al. 2012). The same logic can be used with accelerometry data without validation to speculate on which accelerometry signatures are associated with feeding events (e.g., Naito et al. 2010). Still, we encourage similar methods to be tested on more deep-diving species, avian or not, to assess variation among taxa.

\section{Conclusion}

Despite a small sample size, this study confirmed the potential of accelerometry as an input to neural network models to predict prey-capture rates in a deep-diving seabird, using Hall sensor data as validation. We concur with other studies on shallow-diving species that accelerometry outperforms depth-derived variables at detecting and quantifying prey capture, and provide one of the very few validation on a deep-diving animal.

Supplementary Information The online version contains supplementary material available at https://doi.org/10.1007/s00227-021-03968-y.

Acknowledgements The study was supported financially and logistically by the Institut Polaire Français Paul Emile Victor (program no. 394 "Oiseaux Plongeurs", P.I.C.A. Bost) and the Terres Australes et Antarctiques Françaises. This work was also supported by the Centre National de Recherche Scientifique and the Centre d'Étude Biologique de Chizé. We thank Nicolas Hanuise for its help on the field and in the preparation and analysis of the data; and Jean-Paul Gendner and Nicolas Chatelain (from the Institut Pluridisciplinaire Hubert Curien, UMR 7178 CNRS-UniSTra), who have designed and built the «SMAD», the bio-logger used.

Authors' contributions ÉB-C (corresponding author) did the analysis and writing, $\mathrm{YH}$ collected the data and helped revised the manuscript, and both $\mathrm{C}-\mathrm{AB}$ and $\mathrm{KE}$ helped with the funding and revision of the manuscript.

Funding The study was supported financially and logistically by the Institut Polaire Français Paul Emile Victor (program no.394 "Oiseaux Plongeurs", P.I.C.A. Bost), the Terres Australes et Antarctiques Françaises, NSERC Vanier Scholarship to EBC and John and Pat Warham Studentship from the British Ornithologists Union.

Data availability All data will be available on Dryad upon acceptance of the manuscript.

Code availability Not applicable.

\section{Declarations}

Conflictofinterest There is nocompeting interest for this study.

Ethics approval The ethics committee of the Institut polaire français Paul-Émile Victor approved all field procedures.

\section{References}

Adachi T, Takahashi A, Costa DP, Robinson PW, Hückstädt LA, Peterson SH, Naito Y (2021) Forced into an ecological corner: roundthe-clock deep foraging on small prey by elephant seals. Sci Adv 7(20):3628

Bestley S, Patterson TA, Hindell MA, Gunn JS (2008) Feeding ecology of wild migratory tunas revealed by archival tag records of visceral warming. J Anim Ecol 77(6):1223-1233

Bonaccorso G (2017) Machine learning algorithms. Packt Publishing Ltd

Bost CA, Zorn T, Le Maho Y, Duhamel G (2002) Feeding of diving predators and diel vertical migration of prey: King penguins ${ }^{1}$ diet versus trawl sampling at Kerguelen Islands. Mar Ecol Prog Ser 227:51-61

Bost CA, Handrich Y, Butler PJ, Fahlman A, Halsey LG, Woakes AJ, Ropert-Coudert Y (2007) Changes in dive profi as an 
indicator of feeding success in king and Adélie penguins. Deep Sea Res Part II 54(3-4):248-255

Bost CA, Goarant A, Scheff A, Koubbi P, Duhamel G, Charrassin JB (2011) Foraging habitat and performances of King penguins Aptenodytes patagonicus, Miller, 1778 at Kerguelen islands in relation to climatic variability The Kerguelen Platea: Marine Ecosystem and Fisheries. Société Française d'Ichtyologie, pp 199-202

Brewster LR, Dale JJ, Guttridge TL, Gruber SH, Hansell AC, Elliott M, Gleiss AC (2018) Development and application of a machine learning algorithm for classifi of elasmobranch behaviour from accelerometry data. Mar Biol 165(4):1-19

Brisson-Curadeau É, Elliott KH (2019) Prey capture and selection throughout the breeding season in a deep-diving generalist seabird, the thick-billed murre. J Avian Biol 50(7).

Carroll G, Slip D, Jonsen I, Harcourt R (2014) Supervised accelerometry analysis can identify prey capture by penguins at sea. $\mathrm{J}$ Exp Biol 217(24):4295-4302

Carroll G, Harcourt R, Pitcher BJ, Slip D, Jonsen I (2018) Recent prey capture experience and dynamic habitat quality mediate short-term foraging site fi in a seabird. Proc Royal Soc b: Biol Sci 285(1883):20180788

Catul V, Gauns M, Karuppasamy PK (2011) A review on mesopelagic fi belonging to family Myctophidae. Rev Fish Biol Fisheries 21(3):339-354

Charrassin JB, Kato A, Handrich Y, Sato K, Naito Y, Ancel A, Le Maho Y (2001) Feeding behaviour of free-ranging penguins determined by oesophageal temperature. Proceedings of the Royal Society of London. Series B: Biol Sci 268(1463): $151-157$

Cherel Y, Hobson KA, Guinet C, Vanpe C (2007) Stable isotopes document seasonal changes in trophic niches and winter foraging individual specialization in diving predators from the Southern Ocean. J Anim Ecol 76(4):826-836

Childress JJ, Somero GN (1990) Metabolic scaling: a new perspective based on scaling of glycolytic enzyme activities. Am Zool 30(1):161-173

Chivers LS, Hatch SA, Elliott KH (2016) Accelerometry reveals an impact of short-term tagging on seabird activity budgets. Condor Ornithol Appl 118(1):159-168

Cleveland WS, Grosse E, Shyu WM (1992) Local regression models. In: Chambers JM, Hastie TJ (eds) Chapter 8 in Statistical models in S. Wadsworth \& Brooks/Cole

Crossin GT, Trathan PN, Phillips RA, Gorman KB, Dawson A, Sakamoto KQ, Williams TD (2012) Corticosterone predicts foraging behavior and parental care in macaroni penguins. Am Nat 180(1):E31-E41

Daunt F, Wanless S, Harris MP, Money L, Monaghan P (2007) Older and wiser: improvements in breeding success are linked to better foraging performance in European shags. Funct Ecol 21(3):561-567

Del Caño M, Quintana F, Yoda K, Dell'Omo G, Blanco GS, GómezLaich A (2021) Fine-scale body and head movements allow to determine prey capture events in the Magellanic Penguin (Spheniscus magellanicus). Mar Biol 168(6):1-15

Drazen JC, Seibel BA (2007) Depth-related trends in metabolism of benthic and benthopelagic deep-sea fi Limnol Oceanogr 52(5):2306-2316

Elliott KH, Davoren GK, Gaston AJ (2008) Time allocation by a deep-diving bird refl prey type and energy gain. Anim Behav 75(4):1301-1310

Ellis K, Godbole S, Marshall S, Lanckriet G, Staudenmayer J, Kerr J (2014) Identifying active travel behaviors in challenging environments using GPS, accelerometers, and machine learning algorithms. Front Public Health 2:36
Fauchald P, Tveraa T (2003) Using fi t-passage time in the analysis of area-restricted search and habitat selection. Ecology 84(2):282-288

Gallon S, Bailleul F, Charrassin JB, Guinet C, Bost CA, Handrich Y, Hindell M (2013) Identifying foraging events in deep diving southern elephant seals, Mirounga leonina, using acceleration data loggers. Deep Sea Res Part II 88:14-22

Grémillet D, DellOmo G, Ryan PG, Peters G, Ropert-Coudert Y, Weeks SJ (2004) Off e diplomacy, or how seabirds mitigate intra-specific competition: a case study based on GPS tracking of Cape gannets from neighbouring colonies. Marine Ecol Prog Series 268:265-279

Günther F, Fritsch S (2010) neuralnet: training of neural networks. The R J 2(1):30-38

Halsey LG, Bost CA, Handrich Y (2007) A thorough and quantified method for classifying seabird diving behaviour. Polar Biol 30(8):991-1004

Halsey LG, Butler PJ, Fahlman A, Bost CA, Handrich Y (2010) Changes in the foraging dive behaviour and energetics of king penguins through summer and autumn: a month by month analysis. Mar Ecol Prog Ser 401:279-289

Hanuise N, Bost CA, Huin W, Auber A, Halsey LG, Handrich Y (2010) Measuring foraging activity in a deep-diving bird: comparing wiggles, oesophageal temperatures and beak-opening angles as proxies of feeding. J Exp Biol 213(22):3874-3880

Hanuise N, Bost CA, Handrich Y (2013) Optimization of transit strategies while diving in foraging king penguins. J Zool 290(3):181-191

Hays GC, Ferreira LC, Sequeira AM, Meekan MG, Duarte CM, Bailey $\mathrm{H}$, Thums M (2016) Key questions in marine megafauna movement ecology. Trends Ecol Evol 31(6):463-475

Horsburgh J, Morrice M, Lea MA, Hindell MA (2008) Determining feeding events and prey encounter rates in a southern elephant seal: a method using swim speed and stomach temperature. Mar Mamm Sci 24(1):207-217

Kirkwood R, Robertson G (1997) The foraging ecology of female emperor penguins in winter. Ecol Monogr 67(2):155-176

Kokubun N, Kim JH, Shin HC, Naito Y, Takahashi A (2011) Penguin head movement detected using small accelerometers: a proxy of prey encounter rate. J Exp Biol 214(22):3760-3767

Langrock R, King R, Matthiopoulos J, Thomas L, Fortin D, Morales JM (2012) Flexible and practical modeling of animal telemetry data: hidden Markov models and extensions. Ecology 93(11):2336-2342

Le Vaillant M, Le Bohec C, Prud'Homme O, Wienecke B, Le Maho Y, Kato A, Ropert-Coudert Y (2013) How age and sex drive the foraging behaviour in the king penguin. Mar Biol 160(5):1147-1156

Martin GR (1999) Eye structure and foraging in King Penguins Aptenodytes patagonicus. Ibis 141(3):444-450

Miller PJ, Johnson MP, Tyack PL (2004) Sperm whale behaviour indicates the use of echolocation click buzzes 'creaks' in prey capture. Proceedings of the Royal Society of London. Series B: Biol Sci 271(1554), 2239-2247.

Mori Y, Takahashi A, Mehlum F, Watanuki Y (2002) An application of optimal diving models to diving behaviour of Brünnich's guillemots. Anim Behav 64(5):739-745

Naito Y, Bornemann H, Takahashi A, McIntyre T, Plötz J (2010) Finescale feeding behavior of Weddell seals revealed by a mandible accelerometer. Polar Sci 4(2):309-316

Naito Y, Costa DP, Adachi T, Robinson PW, Fowler M, Takahashi A (2013) Unravelling the mysteries of a mesopelagic diet: a large apex predator specializes on small prey. Funct Ecol 27(3):710-717

Naito Y, Costa DP, Adachi T, Robinson PW, Peterson SH, Mitani Y, Takahashi A (2017) Oxygen minimum zone: An important oceanographic habitat for deep-diving northern elephant seals Mirounga Angustirostris. Ecol Evolution 7(16):6259-6270 
Narayanan A, Desai F, Stewart T, Duncan S, Mackay L (2020) Application of raw accelerometer data and machine-learning techniques to characterize human movement behavior: a systematic scoping review. J Phys Act Health 17(3):360-383

Orgeret F, Péron C, Enstipp MR, Delord K, Weimerskirch H, Bost CA (2019) Exploration during early life: distribution, habitat and orientation preferences in juvenile king penguins. Mov Ecol $7(1): 1-17$

Pichegru L, Grémillet D, Crawford RJM, Ryan PG (2010) Marine no-take zone rapidly benefits endangered penguin. Biol Let 6(4):498-501

Pucci R, Micheli A, Chessa S, Hunter J (2020) Machine learning approaches for identifying prey handling activity in otariid pinnipeds. arXiv preprint

R Core Team (2013) R: A language and environment for statistical computing.

Riaboff L, Poggi S, Madouasse A, Couvreur S, Aubin S, Bédère N, Plantier G (2020) Development of a methodological framework for a robust prediction of the main behaviours of dairy cows using a combination of machine learning algorithms on accelerometer data. Comput Electr Agri 169:105179

Ropert-Coudert Y, Kato A, Wilson RP, Cannell B (2006) Foraging strategies and prey encounter rate of free-ranging Little Penguins. Mar Biol 149(2):139-148

Ropert-Coudert Y, Sato K, Kato A, Charrassin JB, Bost CA, Maho YL, Naito Y (2000) Preliminary investigations of prey pursuit and capture by king penguins at sea.

Sato NN, Kokubun N, Yamamoto T, Watanuki Y, Kitaysky AS, Takahashi A (2015) The jellyfi buff t: jellyfi enhance seabird foraging opportunities by concentrating prey. Biol Let 11(8):20150358

Scheffer A, Trathan PN, Collins M (2010) Foraging behaviour of king penguins (Aptenodytes patagonicus) in relation to predictable mesoscale oceanographic features in the Polar Front Zone to the north of South Georgia. Prog Oceanogr 86(1-2):232-245

Scheffer A, Bost CA, Trathan PN (2012) Frontal zones, temperature gradient and depth characterize the foraging habitat of king penguins at South Georgia. Mar Ecol Prog Ser 465:281-297

Scheff A, Trathan PN, Edmonston JG, Bost CA (2016) Combined influence of meso-scale circulation and bathymetry on the foraging behaviour of a diving predator, the king penguin (Aptenodytes patagonicus). Prog Oceanogr 141:1-16

Schreer JF, Testa JW (1996) Classifi of Weddell seal diving behavior. Mar Mamm Sci 12(2):227-250

Simeone A, Wilson RP (2003) In-depth studies of Magellanic penguin (Spheniscus magellanicus) foraging: can we estimate prey consumption by perturbations in the dive profile? Mar Biol 143(4):825-831

Sutton G, Pichegru L, Botha JA, Kouzani AZ, Adams S, Bost CA, Arnould JP (2020) Multi-predator assemblages, dive type, bathymetry and sex influence foraging success and efficiency in African penguins. Peer J 8:e9380

Takahashi A, Dunn MJ, Trathan PN, Croxall JP, Wilson RP, Sato K, Naito Y (2004) Krill-feeding behaviour in a chinstrap penguin compared to fi Mar Ornithol 32:47-54

Tessier E, Bost CA (2020) Behavioural adjustments during foraging in two diving seabirds: king and macaroni penguins. Mar Biol 167(9):1-11
Trathan PN, Bishop C, Maclean G, Brown P, Fleming A, Collins MA (2008) Linear tracks and restricted temperature ranges characterise penguin foraging pathways. Mar Ecol Prog Ser 370:285-294

Viviant M, Trites AW, Rosen DA, Monestiez P, Guinet C (2010) Prey capture attempts can be detected in Steller sea lions and other marine predators using accelerometers. Polar Biol 33(5):713-719

Viviant M, Monestiez P, Guinet C (2014) Can we predict foraging success in a marine predator from dive patterns only? Validation with prey capture attempt data. PLoS ONE 9(3):e88503

Volpov BL, Hoskins AJ, Battaile BC, Viviant M, Wheatley KE, Marshall G, Arnould JP (2015) Identifi of prey captures in Australian fur seals (Arctocephalus pusillus doriferus) using head-mounted accelerometers: field validation with animal-borne video cameras. PLoS ONE 10(6):e0128789

Wang Y, Nickel B, Rutishauser M, Bryce CM, Williams TM, Elkaim G, Wilmers CC (2015) Movement, resting, and attack behaviors of wild pumas are revealed by tri-axial accelerometer measurements. Mov Ecol 3(1):1-12

Watanabe YY, Takahashi A (2013) Linking animal-borne video to accelerometers reveals prey capture variability. Proc Natl Acad Sci 110(6):2199-2204

Watanabe YY, Ito M, Takahashi A (2014) Testing optimal foraging theory in a penguin-krill system. Proc Royal Soc b: Biol Sci 281(1779):20132376

Watanabe YY, Baranov EA, Miyazaki N (2020) Ultrahigh foraging rates of Baikal seals make tiny endemic amphipods profitable in Lake Baikal. Proc Natl Acad Sci 117(49):31242-31248

Wilson R, Steinfurth A, Ropert-Coudert Y, Kato A, Kurita M (2002) Lip-reading in remote subjects: an attempt to quantify and separate ingestion, breathing and vocalisation in free-living animals using penguins as a model. Mar Biol 140(1):17-27

Wilson RP, White CR, Quintana F, Halsey LG, Liebsch N, Martin GR, Butler PJ (2006) Moving towards acceleration for estimates of activity-specific metabolic rate in free-living animals: the case of the cormorant. J Anim Ecol 75(5):1081-1090

Ydesen KS, Wisniewska DM, Hansen JD, Beedholm K, Johnson M, Madsen PT (2014) What a jerk: prey engulfment revealed by high-rate, super-cranial accelerometry on a harbour seal (Phoca vitulina). J Exp Biol 217(13):2239-2243

Yoshino K, Takahashi A, Adachi T, Costa DP, Robinson PW, Peterson SH, Naito Y (2020) Acceleration-triggered animal-borne videos show a dominance of fish in the diet of female northern elephant seals. J Experiment Biol 223(5):Jeb12936

Zimmer I, Wilson RP, Gilbert C, Beaulieu M, Ancel A, Plötz J (2008) Foraging movements of emperor penguins at Pointe Géologie. Antarctica Polar Biol 31(2):229-243

Zimmer I, Ropert-Coudert Y, Kato A, Ancel A, Chiaradia A (2011) Does foraging performance change with age in female little penguins (Eudyptula minor)? PLoS ONE 6(1):e16098

Publisher's Note Springer Nature remains neutral with regard to jurisdictional claims in published maps and institutional affiliations. 